\title{
Fuzzy Logic Based Speed Controller For a Container Ship
}

\author{
Abdul Qadir ${ }^{1}$, Dur Muhammad, Mukhtiar Unar ${ }^{2}$, Jawaid Doudpoto², Mahmood \\ Khatak $^{2}$
}

\begin{abstract}
:
Speed control of marine ships is one of the leading problems in terms of safety and economy. This research aims at designing a fuzzy logic-based speed controller for a marine ship. The dynamic model of container ship is considered. Fuzzy logic-based approach is employed to control the variations and to maintain the controller performance under the ideal conditions as well as during rough weather. MATLAB is used for simulation. The results show that the proposed controller has enhanced control performance compared to conventional controllers, efficiently confine the influence of the environmental disturbance, ensure perfectly control, and have good robustness.
\end{abstract}

Keywords: Container ship, Speed control, Fuzzy logic, Disturbances.

\section{Introduction}

It is essential for the marine ships to have some sort of speed controller to control and govern the speed of the ship to improve stability and maneuverability of ship during course keeping, course changing and pitching motion. Because while the ship is under the sea conditions, in very short span of time the propeller load will change during the pitching motion of the ship as the propeller may be close to or above the surface of water. Various researchers have contributed in this area. Le Luo et al. worked on electric propulsion system of ship [1]. His work is based on development of PID controller. Y. Luo et al. also worked on electrical propulsion system and tested PI control mode for combined power and speed control of marine ship [2]. Rigatos et al. presented the fuzzy control for adaptive ship steering problems [3]. W Meng et al. presented the Fuzzy Logic technique for dynamic positioning of ship [4]. Tadeusz et al. worked on the effect of wind, waves and loading conditions on speed of ship [5].

The abovementioned research is based on the design of PID or PI controller for electric propulsion, speed and power control, However the speed control of ship under sea is a non-linear and time varying and PID controller is not effective in dynamic behavior, robustness and control. The mass of the container ship, hydrodynamic force and moments also require complex mathematical modelling, whereas the design of Fuzzy logic controller is expert knowledge-based system and widely used by control researchers for ship steering control, dynamic positioning of ship and electric propulsion control. Published studies have never considered Fuzzy logic-

${ }^{1}$ Mechanical Engineering, Faculty of Engineering and Management sciences Isra University Hyderabad

${ }^{2}$ Mechatronics Engineering, Institute of Information and communication Technologies MUET Jamshoro Corresponding Email: aq.channa@isra.edu.pk 
based speed control design for a marine ship. Considering Fuzzy logic in marine ships will be useful in regulating and advancing the speed control of marine ships. This study thus proposes a fuzzy logic-based speed controller which maintains the desired performance in both ideal conditions as well as in presence of disturbances.

\section{Dynamics of a Ship}

A rigid body can be completely defined by six coordinates as shown in Fig. 1 Therefore, six degrees of freedom are necessary to describe the motion of a ship [6] as mentioned in TABLE 1 , where the $x, y$ and $z$ coordinates represent the linear motion along $x, y$ and $z$, and the $\phi, \theta$ and $\psi$ represent the angular motion.

TABLE 1. Notation of ship motion.

\begin{tabular}{|l|l|c|c|}
\hline $\begin{array}{l}\text { Motio } \\
\text { n }\end{array}$ & $\begin{array}{l}\text { Forces } \\
\text { \& } \\
\text { moment } \\
\text { s }\end{array}$ & $\begin{array}{l}\text { linear } \\
\text { \& } \\
\text { angula } \\
\text { r vel. }\end{array}$ & $\begin{array}{l}\text { Positio } \\
\text { ns \& } \\
\text { Euler } \\
\text { angles }\end{array}$ \\
\hline Surge & X & u & X \\
Sway & Y & V & y \\
Heave & Z & w & Z \\
Roll & K & p & $\phi$ \\
Pitch & M & q & $\theta$ \\
Yaw & N & r & $\psi$ \\
\hline
\end{tabular}

\subsection{Container Model}

The mathematical model for a container ship has been presented by Son and Nomoto [8]. The parameters of the container model are given in TABLE 2 [8].
TABLE 2. Container ship parameters.

\begin{tabular}{|c|c|c|}
\hline Parameter & Value & Unit \\
\hline Length & 175 & Meter $(\mathrm{m})$ \\
\hline Breath & 47.17 & Meter $(\mathrm{m})$ \\
\hline Volume & 21,224 & Meter $^{3}\left(\mathrm{M}^{3}\right)$ \\
\hline $\begin{array}{c}\text { Block co- } \\
\text { efficient }\end{array}$ & 0.558 & No unit \\
\hline Ship speed & 16 & Knots \\
\hline Propeller speed & 80 & rev/m \\
\hline
\end{tabular}

State vector of a container ship can be defined as

$\mathrm{x}=[\mathrm{u} v \mathrm{r} \mathrm{x} y \psi \mathrm{p} \phi \delta \mathrm{n}]^{\prime}$

The definitions of all elements of state vector in Eq.1 are given in TABLE 1. The speed of ship can be specified by surge velocity ' $u$ ' and actual shaft velocity ' $n$ ' from Eq. 1 Therefore, the sub-model may be presented as in Eq. 2

$\mathrm{x} \_$prop $=\left[\begin{array}{ll}\mathrm{x}(1) & \mathrm{x}(10)\end{array}\right]$

Where

- $\mathrm{u}=\mathrm{x}(1) \quad \mathrm{x}(1)=7$.

- $\mathrm{n}=\mathrm{x}(10) / 60 \mathrm{x}(10)=80$.

\subsection{Propeller Model}

The mathematical expression which governs the propulsion speed of the propeller is given in Eq. 3 [7]

$$
\mathrm{k} \mathrm{x}=\frac{1}{T_{m}}\left(\mathrm{n} \_\mathrm{c}-\mathrm{n}\right)
$$

Where ' $\dot{n}$ ' is the output of the propeller as shown in Fig 4, 'n_c' and ' $n$ ' are command shaft velocity and actual shaft velocity. $T_{m}$ is the time constant for shaft dynamics. 


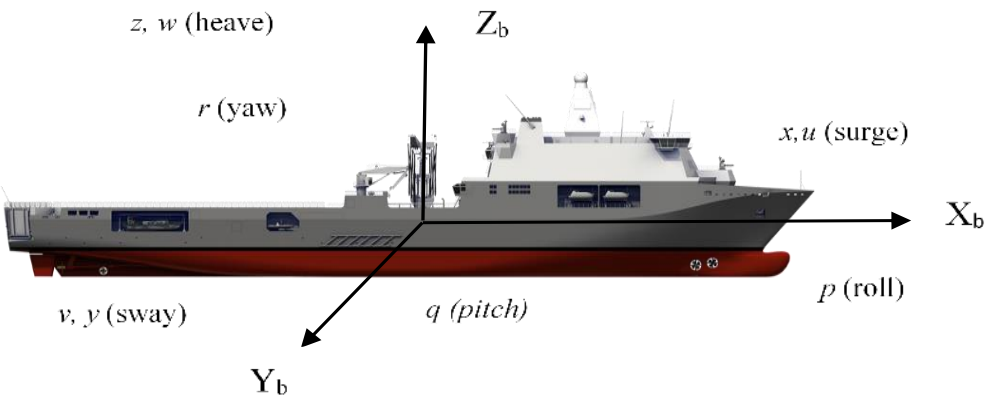

Fig. 1. Body fixed reference frame.

\section{Fuzzy Logic Controller (FLC)}

The fuzzy logic controller is a method of mapping the input states against the output [10]. Fuzzy interface system (FIS) as shown in Fig. 2 is used to map the given input to required output and this mapping provides basis for decision making $[9,11]$. A FLC has three stages namely Fuzzifier, Interface system and Defuzzifier. The fuzzifier is a stage where membership functions are mapped, and a truth value is assigned [13]. In interface system stage set of rules is developed and results are generated by each rule, which are then further processed in defuzzifier, where results from rule base are combined to obtain a crisp output $[12,14]$.

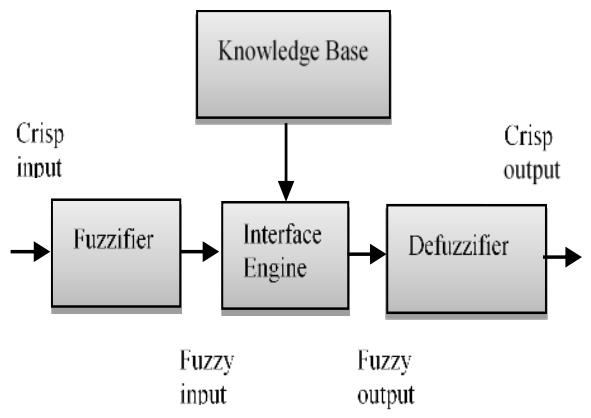

Fig. 2. Fuzzy interface system.

The design of fuzzy logic controller is carried through following steps.

\subsection{Inputs and Outputs for Controller}

The speed of a ship is the function of the shaft speed. The other parameters which are affected by shaft speed are surge velocity ' $u$ ' and actual shaft velocity ' $n$ '. Therefore, the inputs are speed error (u_error) and shaft speed error (n_error) whereas the output is selected as command shaft velocity (n_c). Fuzzy logic controller uses the expert knowledge in the form of linguistic rules. The ranges are tuned by trial and error method. Finally, the ranges given in TABLE 3 yielded the satisfactory performance and the values of fuzzified variables are given in TABLE 4, TABLE 5 and

TABLE 6 respectively.

TABLE 3. Ranges of Input and Output.

\begin{tabular}{|l|l|l|l|}
\hline $\begin{array}{l}\text { Input } \\
\text { vector } \\
\left(X_{\text {error }}\right)\end{array}$ & Speed error & u_error & $\begin{array}{l}-0.07 \text { to } \\
0.01\end{array}$ \\
\cline { 2 - 4 } & $\begin{array}{l}\text { Shaft speed } \\
\text { error }\end{array}$ & n_error & $\begin{array}{l}-0.03 \text { to } \\
4.6\end{array}$ \\
\hline $\begin{array}{l}\text { Output } \\
\left(n \_c\right)\end{array}$ & $\begin{array}{l}\text { Command } \\
\text { shaft speed }\end{array}$ & n_c & $\begin{array}{l}-0.09 \text { to } \\
155\end{array}$ \\
\hline
\end{tabular}

\subsection{Fuzzification of Inputs and Outputs}

Fuzzification is the method of translating the fixed single in fuzzy variables. During the process of fuzzification the inputs and output defined by a linguistic word are divided into subsets. All the input and output subsets are mapped into fuzzy sets taking definite membership functions as shown in Fig. 3. In 
this research 5 sub-sets are defined for input and output, labelled as: big negative $(\mathrm{BN})$, small negative (SN), Zero error (ZE), big positive (BP) and small positive (SP).

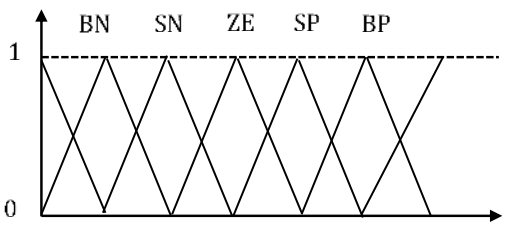

Fig. 3. Mapping of subsets.

Each of these subsets is presented in a way that their values intersect each other as given in TABLE 4, TABLE 5 and

TABLE 6. Each of subsets is mapped into triangular membership function.

TABLE 4. Fuzzy variables and subsets of (u_error).

\begin{tabular}{|c|c|c|c|}
\hline Fuzzy & \multicolumn{3}{|c|}{ (u_error) } \\
\cline { 2 - 4 } Subsets & A & B & C \\
\hline BN & -0.2 & -0.0798 & $\begin{array}{c}- \\
0.06005\end{array}$ \\
\hline SN & -0.0798 & $\begin{array}{c}- \\
0.06005\end{array}$ & 0.04003 \\
\hline ZE & -0.06005 & - & - \\
& & 0.04003 & 0.01995 \\
\hline BP & -0.04003 & - & 0.00028 \\
& & 0.01995 & \\
\hline SP & -0.01995 & 0.00028 & 0.02 \\
\hline
\end{tabular}

TABLE 5. Fuzzy variables and subsets of (in_error).

\begin{tabular}{|c|c|c|c|}
\hline \multirow{2}{*}{$\begin{array}{c}\text { Fuzzy } \\
\text { Subsets }\end{array}$} & \multicolumn{3}{|c|}{ (n_c) } \\
\cline { 2 - 4 } & A & B & C \\
\hline BN & 0.5 & 24.98 & 49.96 \\
\hline SN & 24.98 & 49.96 & 74.96 \\
\hline ZE & 49.96 & 74.96 & 99.98 \\
\hline BP & 74.96 & 99.98 & 124.8 \\
\hline SP & 99.98 & 124.8 & 140 \\
\hline
\end{tabular}

\begin{tabular}{|c|c|c|c|}
\hline \multirow{2}{*}{ Fuzzy } & \multicolumn{3}{|c|}{ (i்_error) } \\
\cline { 2 - 4 } Subsets & A & B & C \\
\hline BN & -0.05 & 0.8006 & 1.633 \\
\hline SN & 0.8006 & 1.633 & 2.49 \\
\hline ZE & 1.633 & 2.47 & 3.334 \\
\hline BP & 2.47 & 3.334 & 4.158 \\
\hline SP & 3.334 & 4.158 & 4.5 \\
\hline
\end{tabular}

TABLE 6. Fuzzy variables and subsets of (u_c).

\subsection{Defuzzification}

Defuzzification is a method to convert the collected output of the linguistic rules into single output value [12]. The maximum degree, average of weight or center of gravity method of defuzzification can be used. For this work centroid defuzzification method is used due to its simplicity and less computation. The mathematical representation of centroid defuzzification method is given in Eq. $4[9,10]$

$$
\mathrm{u} \_\mathrm{c}=\frac{\int \mu_{C}(\mathrm{n}) \cdot \mathrm{n} \cdot d \mathrm{n}}{\int \mu_{c}(\mathrm{n}) d \mathrm{n}}
$$

where $u_{-} \mathrm{c}$ is the single output value, $\mu_{c}(\mathrm{n})$ is the combined membership function and $n$ is the output variable.

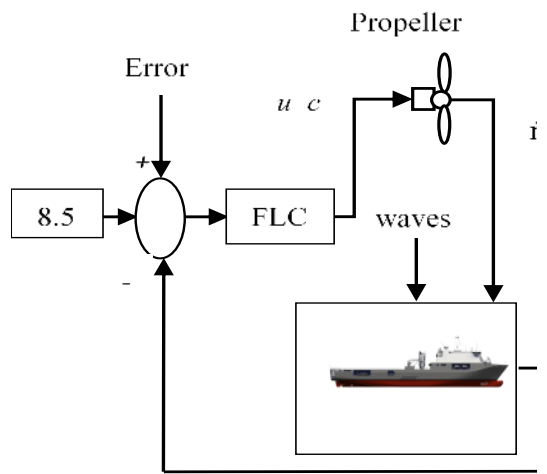

Fig. 4. Fuzzy logic controller. 


\section{Simulation of FLC}

The simulations are carried out by a close lope control as shown in Fig. 4. The performance of controller was tried in calm sea ideal conditions as well as with disturbances (wind generated waves). The simulation results are presented in the Fig. 5 and Fig. 6.

\subsection{Performance of Controller without Disturbances}

The container ship speed controller designed in this research is asked to track the set speed value $8.5 \mathrm{~m} / \mathrm{s}$ as the input signal for the FLC controller with propeller speed (n) of $80 \mathrm{rpm}$. In ideal conditions (without disturbances) the actual speed (blue line) tracking the desired speed (dashed red line) value with minimal steady state error up to -1 and within 350 seconds the actual speed overlaps desired speed value as steady state error becomes 0 . The simulations are carried out on MTALB software and the results are presented in Error! Reference source not found.
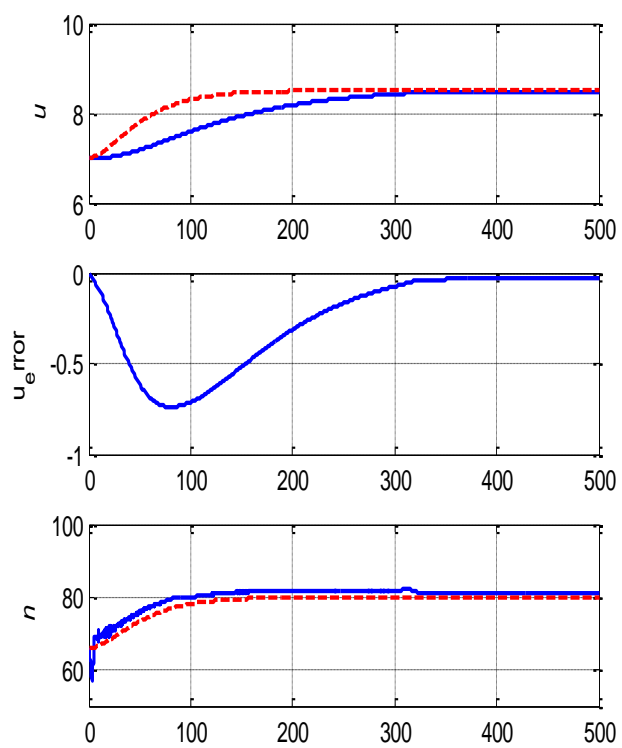

Fig. 5. Simulation of controller in ideal calm se conditions.

\subsection{Performance of Controller with Disturbances}

The Sea conditions are highly dynamic and time variant. There are many disturbances acting on sea ships, i.e, sea currents, depth of water, density of water and wind generated waves etc. in this research wind generated waves are taken as disturbances and the response of controller is tested. The effect of waves can be seen on propeller speed in terms of oscillations, where propeller is trying to overcome the effect of waves to maintain the ship speed. The controller has successfully maintained the ship speed with less than -0.1 error and the propeller speed is stable within 350 seconds. The simulation results are presented in Fig. 6.
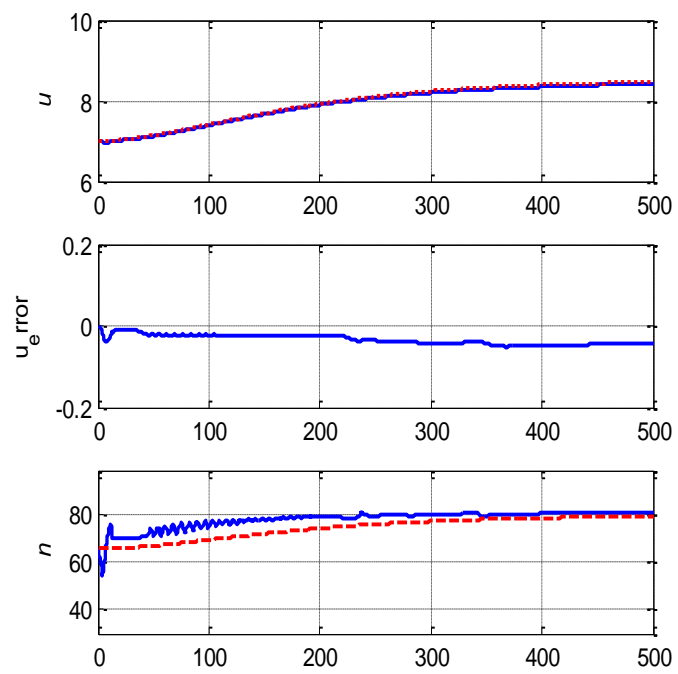

Fig. 6. Simulation of controller with disturbances.

\section{Conclusion}

Due to the complex and non-linear behavior of sea, mathematical modeling of ship maneuvering is difficult. Therefore, expert knowledge based fuzzy logic control system is designed for container ship speed. The controller is tested with calm sea (ideal) conditions and with wind generated waves as disturbances. The designed controller has remained robust and successfully traced the 
desired speed values with and without disturbances.

\section{REFERENCES}

[1] L. Luo, L. Gao, and H. Fu, "The Control and Modeling of Diesel Generator Set in Electric Propulsion Ship," International Journal of Information Technology and Computer Science (IJITCS), vol. 3, pp. 31, 2011.

[2] Y. Luo, S. Lv, S. Kang, and X. Duan, "Combined power and rotating speed control of ship electrical propulsion system in waves," International Conference on Information and Automation (ICIA), 2012, pp. 200-205.

[3] G. Rigatos and S. Tzafestas, "Adaptive fuzzy control for the ship steering problem," Mechatronics, vol.16, pp. 479489, 2006.

[4] W. Meng, L. H. Sheng, M. Qing, and B. G. Rong, "Intelligent control algorithm for ship dynamic positioning," Archives of Control Sciences, vol. 24, pp. 479-497, 2014.

[5] T. Szelangiewicz, B. Wiśniewski, and K. Żelazny, "The influence of wind, wave and loading condition on total resistance and speed of the vessel," Polish Maritime Research, vol. 21, pp. 61-67 10.2478/pomr-2014-0031.

[6] M. N. Farouk, S. Enzhe, M. A.Xiuzhen, “ D6114 Diesel Engine Speed Control: A case Between PID Controller and Fuzzy Logic Controller," Proceedings of 2014 IEEE International Conference on Mechatronics and Automation, August 3 - 6, Tianjin, China.

[7] Q. Sun, J. Chen, "Speed governor design based on fuzzy self-tuning PID method for marine diesel engine," 5th International Conference on Advanced Design and Manufacturing Engineering (ICADME 2015).
[8] T. I. Fossen, Guidance and control of ocean vehicles. John wiley and sons., 1994, ISBN 047194113 pp.445.

[9] B. Purwahyudi and H. A. Saidah, "fuzzy logic controller for volts/hz induction motor control used in electrically driven marine propeller," ISSN-L: 2223-9553, ISSN: 2223-9944 Vol. 4 No. 5 September 2013.

[10] Y. Yang and C. Zhou, "Adaptive Fuzzy control of ship autopilot with uncertain nonlinear systems," Proceedings of IEEE Conference on Cybernetics and Intelligent Systems, Singapore, 2004.

[11] S. Dick, "Toward complex fuzzy logic, Fuzzy systems," EEE Transactions on Fuzzy Systems, vol. 13, no. 3, pp. 405 414, 2005.

[12] M. Jamshaid, A. Titli, L. A. Zadeh, and S. Boverie, "Application of Fuzzy logic," Environmental and Intelligent Manufacturing series, 1997.

[13] M. Santos, R. Lopez, and Cruz de la J.M., "A neuro-fuzzy approach to fast ferry vertical motion modelling," Artificial Intelligence, 2006, vol.19, pp. 313-321. 